\title{
The Application Based on Power Supply Technology in Teaching Course
}

\author{
Jingfeng Liu ${ }^{1}$, Gang Wang ${ }^{2}$, Jianchun $\mathrm{Xu}^{3}$, Hui Chen ${ }^{1}$, Xiaotong Tong ${ }^{1}$, Shaobo He ${ }^{1}$, Guocai \\ $\mathrm{Xu}^{1}$, Baomin Wang ${ }^{1}$, Ying Wang ${ }^{1}$ \\ ${ }^{1}$ Fushun power supply company, State Grid Liaoning Electric Power Co., Ltd. \\ ${ }^{2}$ Information and Communication Branch, State Grid Liaoning Electric Power Co., Ltd. \\ ${ }^{3}$ Dandong power supply company, State Grid Liaoning Electric Power Co., Ltd.
}

Keywords: power supply technology; teaching methods; classroom teaching; practice teaching; curriculum design

\begin{abstract}
To improve the overall quality of students as the goal, we did some exploration and practice of teaching methods and means, which are rational organization of contents, introduction of new teaching methods, enriching classroom teaching and the using of a variety of assessment methods. It made good teaching results. Teaching practice has proved that the implementation of these education reforms can improve students' learning and innovation capabilities and it played an important role.
\end{abstract}

\section{Introduction}

Power technology is the main content of electrical engineering and automation. Its characteristics have close ties with the actual course content, practical and cumbersome to update knowledge quickly. In recent years, based on traditional teaching methods, in order to improve overall quality of students, the rational organization of contents, used of new teaching methods, enrich teaching method in class and use of a variety of assessment methods, and so on. Connecting theory with practice, exploring and practicing the method and means of teaching have achieved good result of teaching.

\section{Rational organization and increasing content}

Power supply technology course includes load calculations, short circuit calculations, equipment selection, relay, high voltage technology, power system operation and maintenance, electrical power quality and other specialized content. Therefore, the organization of the curriculum is very important, and if lectures were handled properly, students will feel cumbersome and boring. So we integrated and optimized the theoretical derivation of unnecessary, and increased the applied practice to improve students' ability of practical application. For example, the three-phase short-circuit power of the physical processes and the impact of three-phase short-circuit current in the infinite capacity of the system are derived, which involve a large number of mathematics and the basic circuit theory and applications. But the actual work don't need so much, therefore, teachers can simplify the derivation of the formula, and only require students to remember the impact factor of the size and impact of current and short circuit current relationship between the periodic components. It will help students to focus on the key point and strengthen the ability of practical application exercise.

With the rapid development of power industry, especially the applications of computer technology in power system emerged a large number of new intelligent switches, relay protection devices and other equipment. These new technologies are badly in need to be introduced to power system engineers and technical personnel. The current widespread used materials don't include this new content, the introduction of the electrical equipment in power systems and industrial and mining enterprises have been phased out. The education taught to students in schools lag far behind social demand, and it can't fully meet social development and employment needs. We interspersed 
in the appropriate teaching field that can reflect the distribution of new knowledge, new technology, and teaching content, such as new high-voltage electrical equipment, computer automation and substation protection devices, which enable students to understand the development of power system cutting-edge knowledge and improve students' interest in learning.

\section{Enrich classroom teaching}

What power systems use most commonly is dry-type air-core reactors whose windings are many single-layer coil twined by aluminum conductor insulated with respectively. The places between two adjacent layers are insulated or heat-radiated with mylarpolyster or by putting air passage at intervals. In fact, the two adjoining levels have approximate electric potentials. Soinsrulation between two adjacent layers is more reliable. After the winding is twined and dried, dip the polyesters and then solidify them. Put antimagnetic brackets which are similar with spider webs both on the top and at the bottom of it, use insulators and arm-braces under the brackets to make them fixed on ground under structure. The reinforcement bars in foundation concrete need to be insulated from each other and they can't compose return circuit, in order to prevent eddy current loss caused by mangneticliakage. In three-phase combination, reactors can be stacked up together, arranged levelly or arranged in the shape of triangles.

\subsection{Combination of classroom teaching, multimedia teaching and practice}

Power technology curriculum has much content and fewer hours. Only rely on the traditional classroom teaching can't complete the task of teaching and improve students' interest in learning. Combining variety of teaching methods together and co-ordinate arrangements rational played a better teaching result. The basic calculation of the power engineering, such as power load calculation, calculation of power network parameters, short circuit current calculation, selection and calibration of electrical equipment and relay setting calculations and so on can still use the traditional teaching methods in the classroom. Teachers can teach the basic calculation for students, after school, students can through homework to digest and expansion. Transformers, high and low voltage electrical equipment only needs teachers to tell students functions and character. After class, teachers can allow students to practice in the production process, and visit the power plant or substation to deepen the structure and physical education principles understanding. For the structure of the cable lines and installation methods and power factor improvement need teachers to tell students methods to enhance their perceptual knowledge. It was proved that electronic teaching and production trinity of teaching practice, not only can improve the teaching efficiency, but also can stimulate students' interest in learning and it will broaden their horizons. It played a multiplier effect for teaching.

The same fundamental purpose of multimedia technology in teaching is to fully and efficiently complete the task of teaching. So the topics of appropriate courseware is to meet the current curriculum requirements and appropriate curriculum, and teaching content should be specific, while the materials should oriented by students' teaching material which in order to facilitate students' prep and review. On this basis, teachers can collect, download the courses or subjects related to the latest data and information, and then to edit, organize them to reflect the courseware, expand the students' knowledge.

\subsection{Combination of multimedia and traditional teaching}

Some of the content of this course, such as relays and low-voltage circuit breaker works, the secondary circuit of the action process are abstract, the effect of the blackboard teaching has little effect. The modern multimedia teaching methods can be used to make the image, vivid, visual images, set text, images and animation become intuitive, image, easy to accept students. Using Flash, PowerPoint and other software to animate these elements to be illustrated multimedia can help students understand abstract knowledge better. In addition, the new additions to the teaching content can use multimedia courseware in the teaching to the students.

Although multimedia teaching is vivid, illustrations, bright, and informative, it can only be used 
as a teaching aid, and it can't completely replace traditional teaching methods which is progressive layers of logical reasoning and flexible regulation. Teachers should combine these two teaching methods and to improve teaching effectiveness.

\section{Variety of teaching methods}

Power plant program is strong practical, cumbersome, and new content is still increased in. According to the actual situation, various forms of teaching methods can be used to fully mobilize the enthusiasm of students. In order to provide students in the classroom a lot of information, you can use multimedia courseware to accelerate the progress of teaching and to improve learning efficiency. Also it can make the classroom teaching to become lively. For example, the media can allow students to visually see the system wiring, electrical equipment, work processes which are not on the content of textbooks to help students' understanding.

\subsection{Course importing method}

A clear and concise guide can effectively stimulate students' interest in learning and desire for knowledge and cohesion attention. It will help to complete the task of teaching and create a good atmosphere and conditions.

(1) Refresher

Importing into new courses can based on the review, and the conclusion of the old classes. For example, in review of learned load calculations and knowledge with reactive power compensation, compensation can be naturally into the distribution network load calculation methods.

(2) Suspense doubts

Teachers can leave suspense to students before teaching them a new concept. This method can help them to form a complete concept in brain. For example, before explaining the concept of grounding and protection of ground, teachers can leave students with real life "protective earth" concept to cause the interest of students.

(3) Link the past and the future

Teachers can use the previous chapter (or in the previous section) to bring out new content of courses. For example, after short-circuit current calculation has been taught, teacher can reiterate the purpose and role of short-circuit calculations to inspire students' transition to a stable thermal stability and electric power parity concept.

(4) Imporingt based on the basic concept

Teachers can use students' basic course content to bring out new courses. For example, before you teach the power line and transformer losses, you can review the circuit in the power circuit components. It will be natural to teach new courses.

\subsection{Guide teaching method}

Teachers should be well prepared, proficient in the subject knowledge, and also think from the perspective of students to design courses. What's more, as a teacher, you also should have a wealth of practical experience. For example, when you are explaining the relay, you can illustrate the cause of the accident or hazard. Then you can explain the theory of content protection.

\subsection{Heuristic teaching method}

Sometimes teachers can be more inspiring during teaching, and try the induction teaching methods to achieve good effect. Asking question can stimulate student's thinking, and improve students' interest and enthusiasm. For example, when you are explaining how the distribution network ensures selective over current protection, teachers can give some inspiration to students, like time steps.

\subsection{Discussion teaching method}

Teacher can ask questions to encourage students to ask questions, to express their views in classroom discussions. For example, when students are studying current protection sensitivity check, 
teachers can organize students to discuss what type of protection was required for sensitivity check. Which kind of protection does not need to be checked? It can enable students to understand better and remember deeper.

\section{Practice-oriented teaching, foster innovation}

Practice students' practical ability to analyze problems and problem-solving capabilities is very important in teaching.

Experimental required in the course can train students in basic skills. In the laboratory, students are able to operate by their own hands, and they have learned a deeper understanding of electrical equipment. Through the experimental course, students can master the circuit breakers, transformers, isolating switches, relays, protection devices and automatic device structure, tuning and testing, and computer applications, it can consolidate and deepen the knowledge taught in the classroom. During the internship process, through on-site talks, visits, internships, they can learn and master the structure, operation and maintenance of the power supply system. More practice teaching can let students combine theory with practice and improve their comprehensive ability.

Design and comprehensive experiment will be completed during the production process. Students in the school can personally design and product in the school, also they can visit production practice mode in modern factory. This practice model greatly mobilized the enthusiasm of students. It can train students to identify problems, analyze problems and problem-solving ability.

\section{Strengthen curriculum design and enhance the training of the project}

Practice students' practical ability to analyze problems and problem-solving capabilities is very important in teaching.

Experimental required in the course can train students in basic skills. In the laboratory, students are able to operate by their own hands, and they have learned a deeper understanding of electrical equipment. Through the experimental course, students can master the circuit breakers, transformers, isolating switches, relays, protection devices and automatic device structure, tuning and testing, and computer applications, it can consolidate and deepen the knowledge taught in the classroom. During the internship process, through on-site talks, visits, internships, they can learn and master the structure, operation and maintenance of the power supply system. More practice teaching can let students combine theory with practice and improve their comprehensive ability.

Design and comprehensive experiment will be completed during the production process. Students in the school can personally design and product in the school, also they can visit production practice mode in modern factory. This practice model greatly mobilized the enthusiasm of students. It can train students to identify problems, analyze problems and problem-solving ability.6 Strengthen Curriculum Design and Enhance the Training of the Project

Curriculum design is another important link of teaching practice besides teaching of the theory and experiment. The purpose is requiring students to master the basic content for distribution system design and design methods. Good curriculum design is an effective way of check student learning outcomes and training ability of students. It could appropriate to add new teaching content for improve the curriculum design and strengthen the ability of students.

The importance in design is teaching effectiveness which focuses on small and medium plant distribution system. Usually the computational load of each plant is given directly, and the students will complete chosen of the transformer capacity, the main wiring diagram design, short circuit current calculation, electrical equipment and current-carrying conductor configuration options, relay setting calculation and design elements, the preparation of design specifications. Also students will draw electrical wiring diagram and schematic diagram transformer protection (or expansion plan). In curriculum design, teachers allow students to think and design independently, and encourage students to access to information. One subject can have a variety of design options. Students are encouraged to use modern means for power supply design. Teachers can encourage students to use AutoCAD, so that their drawing can link to the actual project standards. assessment quality of 
curriculum design consist of the design specifications, quality of the drawing, record of the tutor's answer questions and the progress of curriculum design. It can ensure the performance is reasonable, fair and justice.

Through design of curriculum, it makes students deepen and consolidate the main contents of each chapter of teaching materials and help students establish a complete concept of the power supply system. It will improve the ability of apply their knowledge to analyze and solve problems of students and achieve the goals of develop the awareness of projects and innovation and engineering practice.

\section{Variety assessment methods for improving learning initiative of student}

Examination as an important means of teaching evaluation has an important role in guiding to learning and teaching. The main form of the traditional exam is a written examination that students must close book in limit time. it is not conducive to full examine the ability that the integrated use their knowledge to solve problems of students. Courses of technical of electrical power supply include four parts: the final exam results, homework scores, experimental scores and integrated practice scores, it is a certain percentage of the total score. The final exam score of students can be obtained from two paths: take part in the traditional final exam or apply for exemption. In addition to obtain homework assignments, test, integrated practice areas, seminars and other teaching achievements, students of applications for exemption also select to finish questions of exemption by the main teacher. The questions combine with engineering practice and focusing on ability of innovative design in a number of different stages of teaching. The student of application for exemption as long as complete and pass the exam of these subjects, they do not have to attend the final exam about these course, innovators will get a good scores. The appraisal and evaluative program turns assess of students achievement into the whole teaching process, it makes students take each teaching process seriously, enable students to active learning, avoid the phenomenon of students to cope with exam before the exam and enhance the consciousness of students usually learning.

\section{Conclusions}

The technical of electrical power supply occupies an important position expertise in the electrical engineering, we reform and practice the teaching methods of the technical of electrical power can help students master and application the professional knowledge, also conducive to training more high-quality and innovative electrical professional and technical talent.

\section{References}

[1] Zhiping Tang. Power Supply and Distribution Technology[M]. Beijing: Publishing House of Electronics Industry, 2005.

[2] Huagang Chen. The methods of introduction of new lessons in power supply technology course[J]. ChangJiang Water Education,1998,15(4): 46.

[3] Meilei Lv. The research and exploration of curriculum reform for power supply technology course[J]. Journal of Electrical \& Electronic Education, 2003, (2): 15-17. 